\title{
BIASED UNDERENUMERATION IN CENSUS MANUSCRIPTS Methodological Implications
}

\author{
JOHN B. SHARPLESS \\ University of Wisconsin-Madison \\ RAY M. SHORTRIDGE \\ University of Michigan
}

In the past decade, the census manuscript has emerged as an important source in the study of past societies. Historians and social scientists have increasingly turned to the original census materials in order to develop a richer, more precise understanding of the lives of individuals of the past. At least three major advantages have been suggested for using these records in historical research. First, the census provides direct information on the social and, at times, economic characteristics of a broad spectrum of society. As a result, historians need no longer base their research solely on material written by the articulate elite of the period. ${ }^{1}$ Second, unlike the published census figures, the manuscript links individual people with a variety of factors such as age, sex, or race. In one sense, therefore, the census manuscript serves as a crude surrogate for the modern social survey. Finally, the information culled from the manuscript

Authors' Note: We wish to acknowledge the helpful comments on an earlier version of this paper by Professors Jerome $M$. Clubb and Charles $H$. Tilly and from participants in the Advanced Colloquium, University of Michigan.

JOURNAL OF URBAN HISTORY, Vol. 1 No. 4, August 1975

(C) 1975 Sage Publications, Inc. 
census is readily quantifiable and may be directly applied toward developing and testing various theories concerning human behavior. Thus, recent works in social, urban, and political history extensively employ this rich body of manuscript source material, attempting to draw substantive conclusions about the structure and dynamics of past societies. ${ }^{2}$

A census, however, never enumerates all of the people who should be enumerated. This unavoidable deficiency in the census raises important methodological issues which must be resolved if the potential value of the manuscript materials is to be fully realized. The methodological difficulties associated with a noncomprehensive enumeration in the census perhaps become clearer if one thinks of the census as an unsuccessful attempt at a $100 \%$ sample. ${ }^{3}$ A particularly critical problem is the possibility that the error introduced by the failure to list all of the people is not randomly distributed across the various groups within the population. That is, the sample is biased. The literature drawing upon the census as a basic source of data frequently compares the behavior or condition of groups both at a single time and at several points through time. However, if biased underenumeration is present, it could seriously affect the accuracy of the statistics commonly employed in the comparative analyses. Clearly, distorted statistics can easily lead to fallacious conclusions. This paper approaches this methodological conundrum by assessing the likelihood that bias actually exists in the underenumeration present in the nineteenthcentury census and discusses the implications which the presence of bias holds for analyzing census manuscripts.

\section{THE DIMENSIONS OF ERROR IN CENSUS ENUMERATION}

When using the manuscripts, investigators have, of course, quite properly assumed that the federal censuses of the nineteenth century were not totally accurate enumerations of the population. ${ }^{4}$ Indeed, evidence to support this assumption abounds. In the course of his testimony before a congressional 
committee in 1878 , the chief administrator of the ninth census (1870), General Francis Walker, stated:

The censuses of 1850,1860 , and of 1870 are loaded with bad statistics. There are statistics in the census of 1870 , I am sorry to say, where some of the results are false to the extent of one-half. They had to be published then, because the law called for it; but I took the liberty of branding them as untrustworthy and in some cases giving the reasons therefore at some length. ${ }^{5}$

In addition to this and similar testimony, ${ }^{6}$ there are at least three documented cases of major distortion of census figures in urban areas. For Boston and New Orleans, in 1840, census officials later found it necessary to revise considerably their initial estimates. ${ }^{7}$ In 1870 , both New York and Philadelphia required a second enumeration. ${ }^{8}$ The 1870 census count is also noted for its large-scale underenumeration of blacks, particularly in the South. ${ }^{9}$ More recently, Peter Knights has offered evidence that the extended period allowed for taking the census might have resulted in a minimum of $8 \%$ underenumeration across the board in the antebellum era. ${ }^{10}$

There is also some limited information indicating that contemporary observers were aware of reporting errors biased across social groups in the population. In an 1844 memorial to Congress, the American Statistical Association called for the correction of various errors discovered in the 1840 Federal Census returns. A detailed examination of the returns revealed serious, and often absurd, errors in the reporting and enumeration of the black population. Not only did the enumerators incorrectly report large portions of the black population, but, in many cases where no blacks were reported in the population as a whole, a few "retarded coloreds" were "counted" for good measure. ${ }^{11}$ The census manuscripts reported, for example, that all of the more than three hundred inmates of the State Lunatic Asylum at Worcester, Massachusetts, were black. Subsequent investigation showed that none of the inmates were black. ${ }^{12}$

Nevertheless, it is difficult to know precisely how errors in enumeration may have generally compromised any particular set of census manuscripts. Although the federal census was 
subject to some criticism in the nineteenth century, it was not until the mid-twentieth century that substantial attempts were made to isolate the types of error which result from faulty enumeration. ${ }^{13}$ Generally, two methods have been developed to evaluate the accuracy of the modern census. One method utilizes a resampling procedure or an additional body of collateral data such as birth certificates to evaluate census accuracy on a case-by-case cross-checking basis. ${ }^{14}$ The other method attempts to estimate what various aggregate population figures should be on the basis of demographic analysis. ${ }^{15} \mathrm{By}$ combining the findings of these recent studies with the historical knowledge about the nineteenth-century social environment, it is possible to arrive at a preliminary list for the types of error in the nineteenth-century census manuscripts.

To begin with, enumeration error can be usefully defined in terms of two major categories. Failures in enumeration which conceivably should (barring any conditional factors) fall equally across the total population are called errors of "uniform underenumeration." Failures in enumeration which are conditioned by particular characteristics either of the population or of the enumeration area result in what we call errors of "differential underenumeration." Presumably, the first major category of error, uniform underenumeration, would have little effect on an analysis other than introducing random variance or "noise" into the results. Differential underenumeration, on the other hand, constitutes a serious problem by insinuating bias into the statistics-a factor which must be considered when evaluating any results obtained from census manuscript analysis.

Uniform underenumeration usually stems from inefficiency on the part of the census officials or their procedures. Here one might include a whole range of problems which have decenially plagued the census: poorly qualified enumerators, weak supervision, and the piece-work wage incentive system. ${ }^{16}$ In the nineteenth century there were also the additional problems associated with the protracted period during which the enumeration took place. $^{17}$ Often more than three months were required to conduct a census in the pre-Civil War period. For statistical purposes, it seems both practical and reasonable to 
assume that errors introduced by procedural inefficiencies were both uniformly distributed across the population and rather constant over time. Procedural errors, therefore, relate only tangentially to the problem of bias.

The other area of underenumeration-the differential selection of individuals from the total population conditioned by a set of economic, social, or areal variables-poses a more serious problem. Relatively high levels of differential enumeration of this sort could distort group-level estimates such as mean values, standard deviations, persistence rates, and dependency ratios. This may result in specious conclusions based upon comparisons among subgroups within the total census population. The difficulty clearly lies in ascertaining the extent of bias more precisely by specifying the relative rates of differential selection among the various subgroups in the actual population. Knowledge about these kinds of errors in the census has greatly increased in recent years as census officials have sought to assess the completeness of coverage for blacks and other racial minorities in the more recent censuses. In general, the modern census underreports certain age groupings, underenumerates men relative to women, and seriously undercounts the nonwhite population. Underenumeration also seems to be a function of population density. Finally for socioeconomic reasons, there is a clustering effect aggravating the biases along age, sex, and race dimensions.

Although error and bias due to improper age reporting take on a number of specific forms, all result in what demographers call age heaping: "the tendency for ages to be reported so that the proportion of persons in some age groups is overstated and the proportion in others understated."1 8 Age heaping found in the aggregate census figures can result from an artificial clustering of individuals at certain specific ages and from a systematic underenumeration at certain age levels. In the first case, the individuals are counted, but they incorrectly report their ages; and in the latter, they are not counted at all. The most aggravated form of this reporting error is the tendency to cluster at certain digits within the broader ten-year age groupings, particularly zero and five. For example, although an 
individual's actual age is 32 , the recorded figure is either 30 or 35. Of significance for those using nineteenth-century census materials, is that age reporting error increases as one moves back in time. ${ }^{19}$ Equally disturbing is the research of Ansley J. Coale which shows a sizeable difference in the magnitude of age heaping between whites and nonwhites; that is, the biases in reporting toward selecting certain ages are further exacerbated by the mere factor of the respondent's race. ${ }^{20}$

In addition to failures to report age properly, census-taking practices can also produce differential enumeration at various age levels. If the findings of the modern census evaluation studies are a guide, then historians should anticipate considerable variation in enumeration across the age distribution. Moreover, males more than females seem to be subject to this kind of underenumeration. As one would expect, there are differences by race as well. Table 1 displays some current estimates of net understatement of the census totals due to underenumeration in the 1960 and 1950 censuses. These estimates were prepared by Jacob Siegel and Melvin Zelnik of the U.S. Bureau of the Census. ${ }^{21}$

For white and nonwhite population alike, underenumeration is particularly aggravated for males in their twenties and thirties. For nonwhite males in the age group 30-34, the underenumeration rate is nearly six times greater than that of their white counterparts. Females in the age group 15-19 show a similar white-nonwhite difference.

The extent to which this kind of enumeration error exists in nineteenth-century census manuscripts is difficult to determine. ${ }^{2}$ There is generally only passing reference to enumeration errors in the nineteenth-century printed census. However, the chief administrator of the 1870 census did comment briefly on the apparent age-related error in the number of infantsunder-one recorded in the census. Countering the prevalent belief that infants were simply "overlooked" in the enumeration process, General Walker suggested "that 'the baby' in the house is generally the last to be forgotten; and that such omissions are far more likely to occur in respect to children absent at school or in trade." ${ }^{3}$ Walker ascribed the enumera- 
tion error in infant age statistics to the "rounding off" phenomenon. ${ }^{24}$

Nevertheless, Walker's declarations on the matter did not end the concern of census officials about the gross underenumeration of infants. ${ }^{2} 5$ It was not unti the Infant Enumeration Study of 1950, however, that the problem was examined in any serious way. The analysis in this study was concerned with infants born in the three months immediately preceding the 1950 census enumeration. Despite this limitation, ${ }^{26}$ the results of the study are striking and of particular relevance to this discussion. The study revealed that about $96.4 \%$ of the infants born in the first three months of 1950 were subsequently recorded in the 1950 census records. Furthermore, in greater than $80 \%$ of the cases where the infant was excluded from the census count, the parents were uncounted as well. There was, however, considerable variation in the selection process across various subgroups in the overall population. There was some slight variation by region as well, the South showing the highest underenumeration rate $(5.3 \%)$. It also appears that the age of the mother had some effect on the probability of inclusion. The children of women under 25 were excluded more often than those with mothers over that age. Not too surprisingly, the educational level of the mother also had some effect on the chances of enumeration. ${ }^{27}$

More important for historical census-based studies, the effects of economic status and race on enumeration rates were shown to be most pronounced. For the sample as a whole, approximately $97 \%$ of the white infant population was properly recorded in the census, while only about $94 \%$ of the nonwhite infants was included in the enumeration process. When the sample was sectioned by race and occupation of the infant's father, there was not only an obvious disparity between the white and nonwhite populations, but it was also clearly evident that the probability of the nonenumeration of an infant increased at the lower economic strata for both groups. The infants of minority group parents, who were also of working-class background, had more than a $15 \%$ chance of exclusion from the 1950 census count. A white infant from the same social background ran 


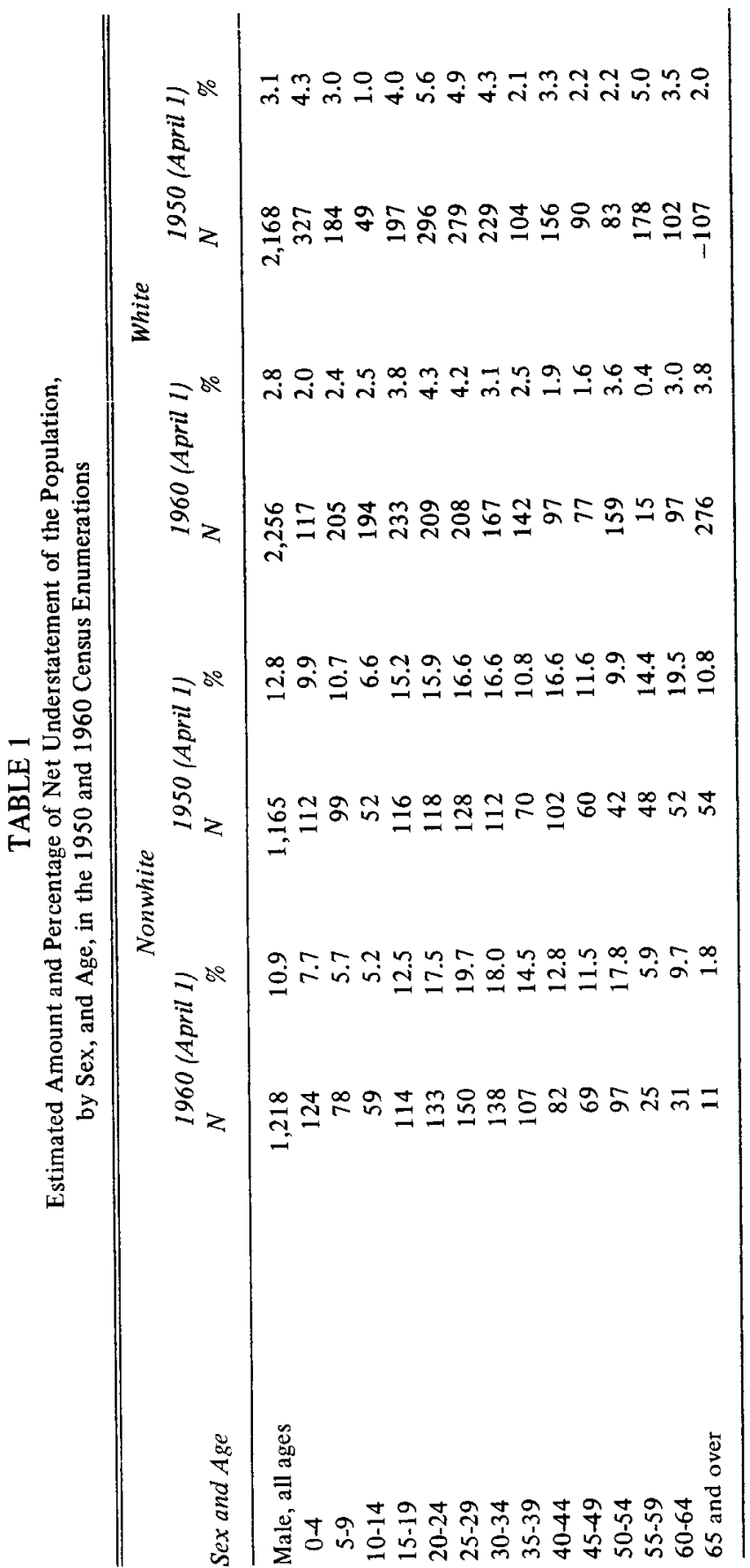




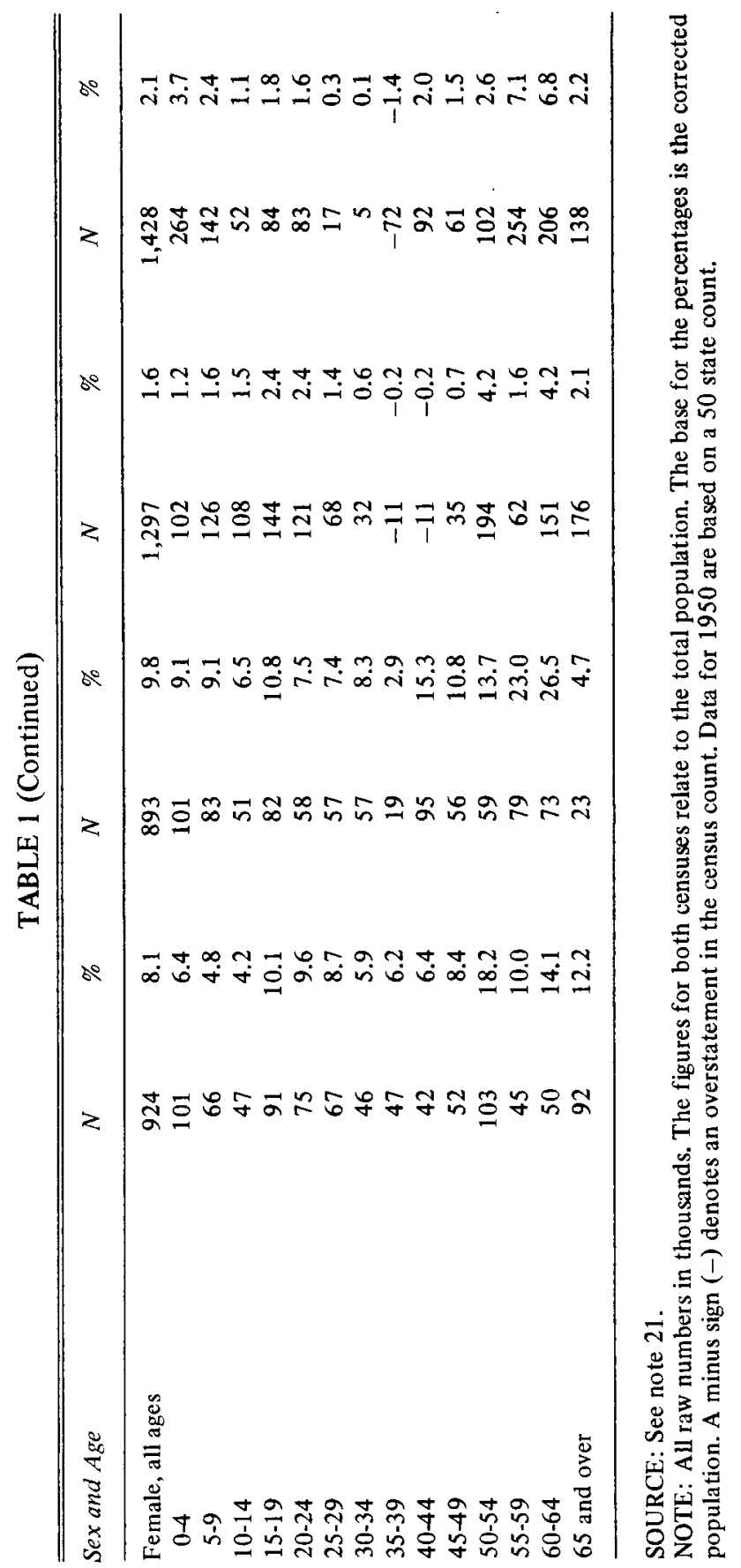


about a $7 \%$ chance of being excluded. As one would expect, the infant child of a white, professional family faced the possibility of exclusion of only about $2 \% .^{2}$

\section{THE LIKELIHOOD OF BIAS IN EARLY CENSUS MATERIALS}

Assuming that interracial enumeration differences hold for immigrant and ethnic minorities in the nineteenth century is a serious step to take. Many of the important questions addressed by recent scholarship using the manuscript census focus directly on immigrant and native differences in behavior in the urban setting. The presence of bias could seriously compromise their findings and require a revision of their interpretations.

One way of further assessing the need for assuming bias is to determine whether conditions which presently result in underenumeration of racial minorities approximated the situation one would expect to find in nineteenth-century ethnic neighborhoods. It should be stressed that there is some evidence that the improper enumeration of blacks and other racial minorities in our recent censuses was partly a function of prejudice. Nevertheless, it is the concomitant economic and demographic factors which seem to account for most of the resulting bias in the census. ${ }^{29}$ It is the conditions of poverty-congested and substandard housing, irregular work and leisure patterns, and low educational attainment--which promote the work and leisure patterns and low educational attainment-which promote the atmosphere in which census underenumeration is likely to occur. Racial minorities are underenumerated presently because blacks, represented among the disadvantaged. Clearly, many immigrant groups were forced to endure a similar environment in the nineteenth century. It seems unnecessary, therefore, to enter into the current debate over whether ethnic groups in the nineteenth century labored under the same kind of hostility as is faced today by racial minorities. It is only necessary to show that the social conditions of immigrant life were such so as to suggest a high probability of underenumeration. 
Immediately following both the 1950 and 1960 enumerations census department officials resurveyed selected portions of the population in order to explore more precisely the sources of census error. It is clear that the post-enumeration surveys did rather well in locating missed living quarters-unenumerated buildings, apartments, and rooms. They were much less effective in locating individuals missed within living quarters already correctly identified. On the basis of these results, however, it appears that the probability of missing a living unit in the census count was greater in sparsely settled rural areas and very large cities (a million or more) than in suburbs, small cities, and towns. ${ }^{30}$ Evidently, both population density and building density affect enumeration effectiveness.

Urban areas also show a higher incidence of what census officials call "close-out cases." These are the households for which no direct information can be obtained; instead, neighbors, janitors, or "friends" are questioned concerning the sex, age, and race of the unknown occupants of such households. The Enumeration Time and Cost Study in 1960 showed that "people in large cities are harder to find at home, and as a group, appear to be somewhat less cooperative than people in smaller communities." ${ }^{11}$ Similar problems faced census officials in the nineteenth century. In many larger urban areas, where it was common for both the household head and the spouse to be employed away from home, enumerators found it necessary to interview servants, lodgers, neighbors, or in the case of many working-class families, the children left at home during the day. ${ }^{32}$

There are also individuals who are missed in the census count and in the subsequent attempts at resurveying the population simply because they reside in places which fall outside the Census Bureau's definition of "residence." Abandoned and condemned housing, rooms in the back or basement of "exclusively retail" establishments, pool halls, bus stations, and the like are generally considered outside the residential universe. Nevertheless, we know that presently, as in the past, many people find it necessary to live in such places. It as hard to estimate what portion of the population is excluded for this 
reason. One source has suggested that the difference between the demographers' estimates of underenumeration and those provided by the Post-Enumeration Survey is a rough estimate of both those individuals residing in obscure quarters as well as those unenumerated persons in correctly identified households. Separating these two components is difficult. However, data from the Infant Enumeration Study would suggest that occupational status determined in large part whether one was excluded simply for residing in a place deemed "obscure" by census officials. Laborers, for example, were twice as likely to be excluded for living in unrecognized quarters as were professionals. $^{33}$

Of equal importance for the differential enumeration among disadvantaged groups is the undercounting which occurs within a properly identified dwelling unit. In this case, the enumerator locates the living quarters, but incorrectly enumerates the individuals residing there. The Post-Enumeration Survey results show "that persons loosely attached to the household, members of the extended family and nonrelatives, were more likely than the household head, wife or children to be missed in the census." 34 Lodgers and "extra families" residing within any particular living unit were also subject to higher rates of exclusion. ${ }^{35}$ In such cases, the individual is excluded either through some misunderstanding or because of intentional deception on the part of the respondent. In the first instance, cultural or language barriers, complicated or confusing instructions, or simply a lack of tact on the part of the enumerator can result in an inaccurate accounting of the household. Of equal importance however, is the fear of identification. All assurances to the contrary, many people do not trust the motives of the census. Again, the aggravation of this type of "error" is to be expected among impoverished or outcast minority groups. It is at this point that the effects of prejudice and racism are most likely to be felt. Members of the family, particularly males, are "protected" from enumeration for fear that subsequently, they can be taxed, drafted, or arrested. There is some evidence that nineteenth-century officials were aware of this problem when 
they tactfully dropped the title of "marshal" for that of "census enumerator." 36

The social historian working with nineteenth-century census manuscripts can expect that individuals in highly congested areas were subject to increased rates of underenumeration and recording error. Further, because of the general social and economic conditions in which both racial and ethnic minority groups lived, there were compound forms of census underenumeration. ${ }^{37}$ Indeed, General Walker's comments evidence a clear awareness of the problem:

When it is considered how many thousands of persons in every large city, how many tens of thousands in a city like New York, not only live in boarding houses, but change their boarding houses at every freak of fancy or disgust, not to speak of those who leave under the stress of impecuniosity and therefore are not likely to leave their future address or advertise their residence, it will be seen how utterly unfitted is such a system of enumeration to the social conditions of the country at the present time. ${ }^{38}$

\section{THE EFFECTS OF ENUMERATION BIAS ON STATISTICAL ESTIMATES}

Whether the presence of biased underenumeration poses a serious methodological problem must be judged in terms of one's research objectives. This type of error may not affect some areas of micropopulation studies such as family reconstruction. On the other hand, biased underenumeration renders suspect comparisons made between parameters of various population groups. For example, when examining the composition of a population at a given time, the proportions obtained from the census will be in error to the degree to which underenumeration is biased across the social groups of interest. Also, when the goal is to analyze change over time, the rates computed from the census manuscripts will be incorrect if biased underenumeration is present along the dimensions being considered. If the underenumeration of the population is sufficiently large, or if the magnitude of underenumeration varies markedly across social groups, then conclusions derived 
from comparing means, proportions, persistence, migration, or other population parameters could be spurious. ${ }^{39}$ This possibility necessitates serious efforts to determine not only the direction of biases in the census but also their magnitude so that the researcher can control for their effects.

The danger posed by the presence of underenumeration and a suggestion of a type of strategy for coping with it can be best illustrated by a discussion of the persistence and migration measures currently employed by demographic and urban historians for understanding the social fluidity of past societies. "Persistence" denotes the behavior of that portion of a population which continues to reside in a given community from one time to another. "Out-migration" refers to the behavior of that proportion of the population which moves to a different locality during the period under study. However, these two categories do not encompass the entire population-people not only stayed or moved, but they also died. Thus, the total population selected in a sample at any given time can be categorized as to whether they persisted, migrated, or died by a future date. For ease of exposition, this statement can be represented by the following equation:

$$
P=1-(M+D) \text {, }
$$

where $P$ is the persistence rate, $M$ is the migration rate, and $D$ is the death rate for any given population.

Unfortunately, the researchers working with historical census data cannot obtain the true values for these rates. One can only obtain the proportion of the population which is selected from the census in one time which can be traced in the records at a subsequent time. That is to say, the historian does not measure the mobility behavior of people directly, but instead merely calculates the proportion of a sample which is to found in later census records. This statement regarding what the researcher can actually compute directly from the census may also be represented in the form of an equation:

$$
\mathrm{T}=1-\overline{\mathrm{T}},
$$


where $T$ is the percentage of individuals who can be traced in the records, and $\bar{T}$ is the percentage which cannot be traced in the records.

The methodological task facing all historians, whether they use literary or digitalized material, is to match the concepts which are of interest with the available data. For the historians working with census materials, the task is to move from the values readily calculated from equation [2] to reliable estimates of the desired values in equation [1]. As a practical matter, in connecting the census manuscript data to the concepts of persistence and migration, the demographic historians have generally assumed that-if people do not die or move-they are to be found in the manuscripts for the subsequent census. Symbolically expressed, the underlying assumption of this practice is:

$$
\overline{\mathrm{T}}=\mathrm{M}+\mathrm{D} .
$$

Again, $\bar{T}$ is the untraceable rate, $M$ is the migration rate, and $D$ is the death rate. In operationalizing the analytical concepts, the proportion of the people who are not traced in a subsequent census is viewed as the sum of the proportions found for the two categories, migrating or dying.

In some cases, one is also interested in refining the estimates for the proportion of the population who migrated. It is felt that migration rates, particularly for various subgroups in the population, may be valuable clues for identifying the causal elements behind the movements of populations. The migration rate can be readily calculated from the operational definition symbolized in equation [3] by adding the death rate to the persistence rate and subtracting the resulting sum from 1 .

$$
M=\bar{T}-D
$$

Given this operational identity to ascertain the migration rate, the researcher needs to obtain a reliable estimate in some direct manner or, by using equation [4], find some appropriate estimate for the death rate. One approach for determining the 
migration directly is by attempting to trace migrants from a community to other areas. ${ }^{40}$ This approach is not only tedious and time-consuming, but offers no assurance that an accurate migration rate can be ascertained. The analyst can seldom be confident that he or she has indeed tracked down each individual who left the community. Consequently, estimating the death rates for the sample seems to constitute a more desirable means for solving equation [4], and several techniques have been suggested for calculating the death rates. ${ }^{41}$ With the traceable rate known, and the death rate known, the value for the migration rate readily follows. And, referring to equation [1], by summing these two rates and subtracting from 1 , one obtains the persistence rate.

These persistence-migration formulas used in the literature are inadequate because they fail to contain an element for underenumeration, an artifact of the data. Without underenumeration being explicitly in the equation, its effects cannot be controlled. The proportion of the sample which is untraceable in a subsequent census is composed of those who died, moved, and who were not counted in the next census. Again, expressed in terms of our equations:

$$
\vec{T}=D+M+U \text {. }
$$

When the underenumeration element is added, the formula for the migration rate becomes:

$$
M=\bar{T}-(D+U)
$$

The persistence rate, of course, should be calculated by:

$$
P=1-(D+M+U)
$$

where $M$ is the migration rate, $\bar{T}$ is the untraceable rate, $D$ is the death rate, and $U$ is the underenumeration rate. That is, unlike the method currently employed, the appropriate equation for the migration rate must control for underenumeration. Migration equals the untraceable rate less the sum of the death and 
underenumeration rates. Similarly the true persistence rate formula must contain an element for the deficiency in the data, underenumeration, as well as the actuarial categories of persistence, migration, and death. If underenumeration is relatively large, one would overestimate the level of migration which is attributable to the population unless underenumeration is included in the computations. When these appropriate procedures are used, the magnitude of the migration estimate is reduced by the extent of underenumeration in the records. Similarly, when the extent of underenumeration is sizeable, then one underestimates the proportion of the people who were remaining in the area unless underenumeration is controlled. The correct procedure results in an increase in the persistence rate equal to the degree of underenumeration in the records.

Underenumeration also poses a problem when one compares the persistence or migration rates for subgroups within the population. The critiques of more modern censuses indicate that the probability of finding a given individual selected from one census in a later census varies systematically according to characteristics of the individual. That is, one cannot assume a constant probability of underenumeration for individuals within the sample. Again, referring to the equations, subscripts must be added to the formula for persistence:

$$
P_{j}=M_{j}+D_{j}+U_{j}
$$

where $\mathrm{P}, \mathrm{M}, \mathrm{D}$, and $\mathrm{U}$ refer to the persistence rate, migration rate, death rate, and underenumeration rate, respectively, for the $j$-th group. Clearly, if underenumeration is biased across subgroups-that is, $U_{a} \neq U_{b}$-then the estimates for the persistence rates must be adjusted accordingly. If it is assumed that underenumeration is evenly distributed across the population and it in fact is not, then one's substantive conclusions could be seriously in error. 


\section{MEASURING THE MAGNITUDE OF ENUMERATION ERROR}

Accurate estimates for the extent to which underenumeration is present in the census are difficult to obtain. The modern census authorities have developed two general approaches to the problem. One involves retaking the census for a sample population and comparing the results with the original comprehensive census. ${ }^{42}$ Researchers dealing with historical censuses do not, of course, have recourse to this procedure, but a method involving a case-by-case cross-checking of census manuscript records with other population lists may provide a rough surrogate. These additional records might very well contain the types of underenumeration to be expected in the census, so a careful method would have to be devised. The second approach used in accuracy checks of modern censuses rely upon inferences drawn from demographic analysis of aggregate census records. ${ }^{43}$ Because it does not require assuming high levels of accuracy in collateral population lists, this method may be a more fruitful strategy for approaching the historical censuses. Nevertheless, until estimates are obtained regarding the general rate of underenumeration in the earlier census manuscripts, the figures presented in the scholarly literature pertaining to population turnover or churning are clearly suspect. ${ }^{44}$ Substantive conclusions about the general movement of a population through time require that explicit controls must be placed upon the underenumeration factor.

There also seems to be no way to estimate the magnitude of underenumeration for groups within the population directly from the census material alone. ${ }^{45}$ However, it is possible to detect some types of enumeration error and to determine whether that error is nonrandomly distributed across social groups by checking the internal consistency of certain census figures. Using the relative bias in this error and drawing upon the findings obtained from analyses of modern censuses, it is possible to obtain an estimate for the magnitude of bias across certain social groups. This section uses one detectable type of internal error, variation in adjusted age ratios, as an indicator of 
the presence of underenumeration within three social groups. If the variation in the adjusted age ratios is nonrandomly distributed across the groups, then we will presume that underenumeration is similarly biased. Clearly, the argument of proof is not closed according to the canons of logic because the error is due to both misreporting and underenumeration and not merely to underenumeration alone. However, the circumstances pertaining to taking a census which give rise to the error which can be directly detected are those which contribute to the underreporting of various groups within the population. Notwithstanding the fact that this approach does not produce a direct proof, it does permit one to draw a probable conclusion based on an empirical study of the census itself coupled with a realistic understanding of the types of error which unavoidably result from the inadequacies of census-taking practices.

In this analysis we compare the variation in age ratios for white native males, black native males, and white foreign males. (Other groups defined by income, geographic area, or other criteria are also likely dimensions among which one could expect differential enumeration error.) An age ratio is calculated by dividing the number of people in a five-year age bracket by the average of the number of people in that and the two adjacent age brackets. When dealing with a closed population, the age ratios should approximate unity. However, Coale identifies three factors which would produce age ratios which depart from unity:

The first factor is the tendency (if any) of typical mortality experience to produce a strongly non-linear age distribution. This factor seems to be unimportant up to very advanced ages... . The second factor is any temporary variation in birth or migration rates which produces an unusually large cohort. The third factor is the tendency for ages to be reported so that the proportion of persons in some age groups is overstated and the proportion in others understated. ${ }^{46}$

By using appropriate calculations presented by Coale, the age ratio can be adjusted to control for these factors. The resultant 
adjusted age ratios gauge the relative under- or overenumeration of a given age bracket relative to the adjoining brackets.

Figures 1-3 present the adjusted age ratios for males 10 years old to 70 for the 1880,1890 , and 1900 U.S. censuses by ethnic groups-native born blacks, native born whites, and foreign born whites. An examination of the graphs indicates that for each census the enumeration for the foreign born males are internally inconsistent to a greater degree than the black native born males' enumeration which is, in turn, more inconsistent than that found for white native born males. That is, the error in the age ratio is biased across the three ethnic groups.

In order to facilitate comparison of the fluctuation in the three groups, Table 2 presents two statistical measures which

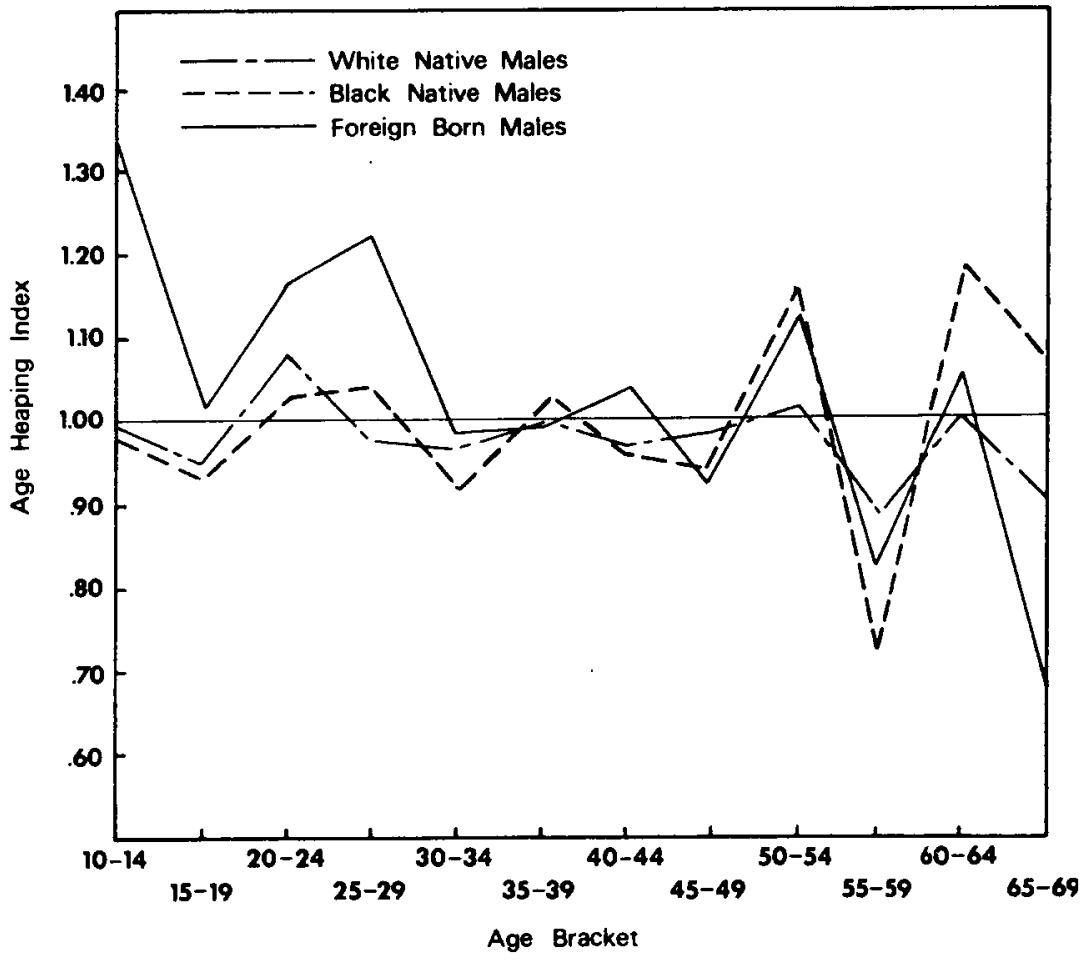

Figure 1: Age Heaping Index for Males by Ethnic Group, 1880 


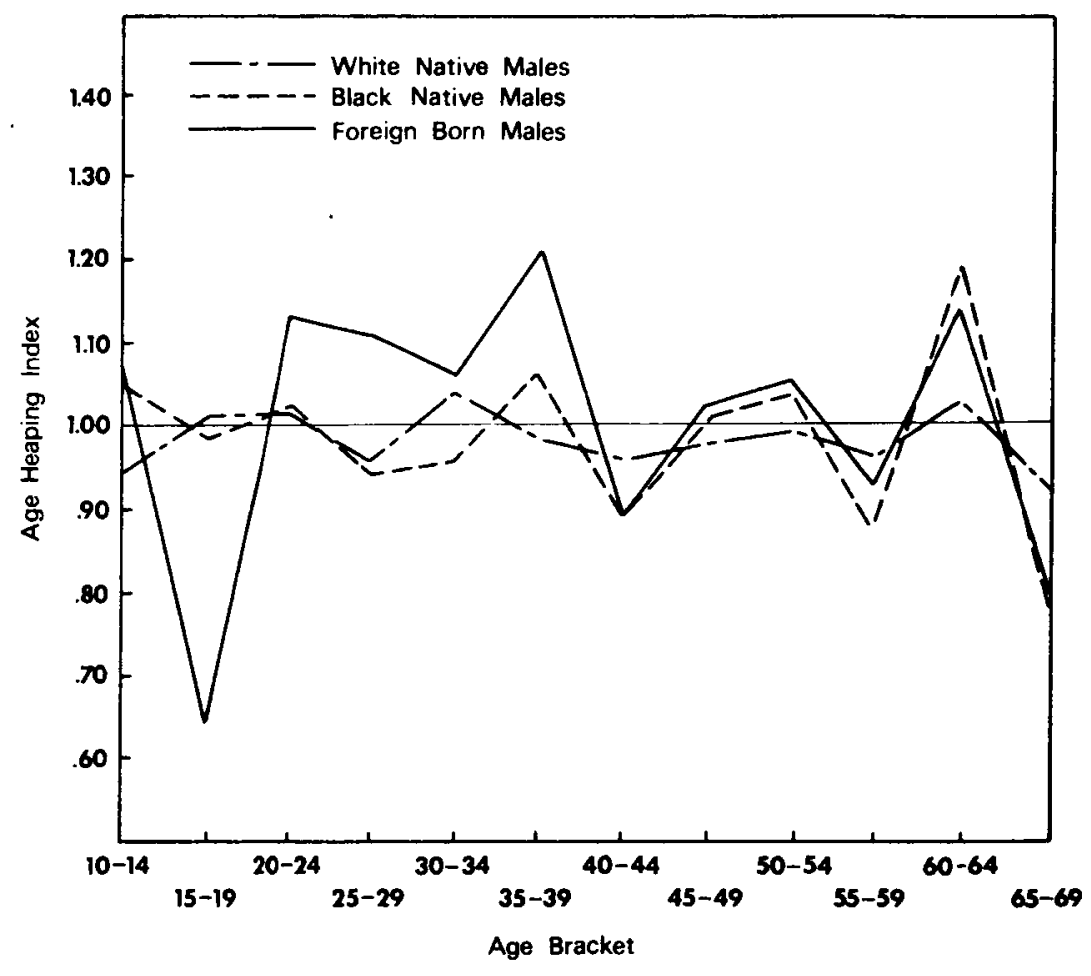

Figure 2: Age Heaping Index for Males by Ethnic Group, 1890

summarize the variance in the adjusted age ratios. The second column contains the standard deviation of the adjusted age ratios for each group in each census. The third column contains the coefficient of variance (the standard deviation divided by the mean) for each group in each census. The coefficient of variance standardizes the amount of fluctuation in the adjusted age ratios as a proportion of the mean. As a result, the coefficient is a statistic which can be used to compare the extent of variance between groups and across a series of censuses.

The coefficients of variance show fluctuations in the adjusted age ratios two or three times greater for black native males than for white native males. The average coefficient for white natives 


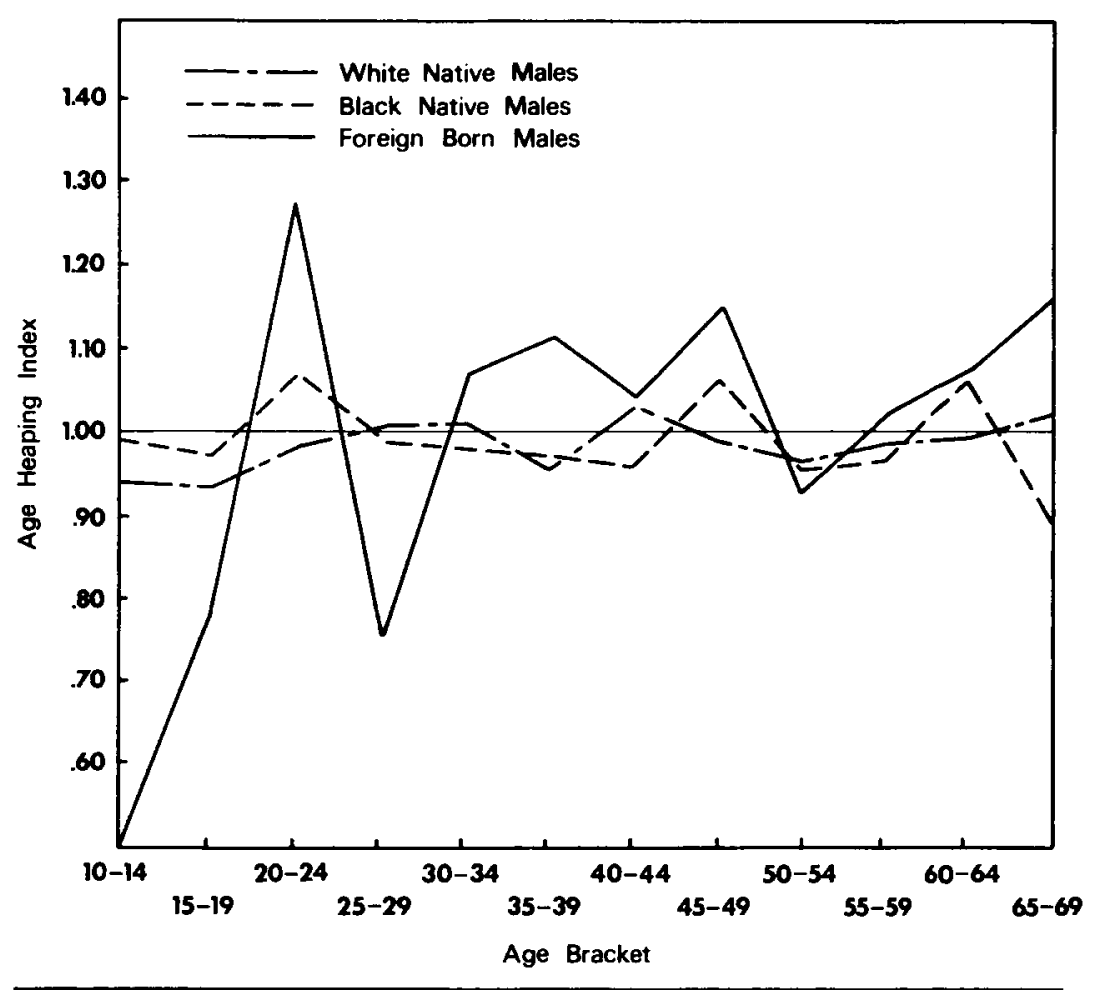

Figure 3: Age Heaping Index for Males by Ethnic Group, 1900

across the three censuses is $3.9 \%$, and the mean for blacks is 9.3\%. In comparing white native males and foreign born white males, the variation in the adjusted age ratios is on the whole four or five times greater for the foreign born than for the native born males. The mean coefficient of variance for the foreign born for the three censuses is $19.8 \%$ as compared to $3.9 \%$ for the native born. Moreover, there is about twice as much fluctuation in the error found for the foreign born as there is for the black native born males, $19.8 \%$ and 9.3\% respectively. These statistical measures corroborate the impression gained by visually appraising the figures; the internal error within these nineteenth-century censuses is biased in its distribution across the three selected groups of males. The error 
TABLE 2

Descriptive and Summary Measures: Age Heaping Index for Whites, Blacks, and Foreign Born Males, 180-1900

\begin{tabular}{lccc}
\hline \hline & Mean & $\begin{array}{c}\text { Standard } \\
\text { Deviation }\end{array}$ & $\begin{array}{c}\text { Coefficient } \\
\text { of Variance }\end{array}$ \\
\hline 1880 & & & \\
Whites & 0.9814 & 0.0529 & $5.4 \%$ \\
Blacks & 0.9990 & 0.1235 & 12.4 \\
Foreign Born & 1.0309 & 0.1752 & 17.0 \\
1890 & & & \\
Whites & 0.9853 & 0.0356 & $3.6 \%$ \\
Blacks & 0.9839 & 0.1023 & 10.4 \\
Foreign Born & 1.0080 & 0.1618 & 16.1 \\
1900 & & & $2.9 \%$ \\
Whites & 0.9840 & 0.0285 & 5.1 \\
Blacks & 0.9929 & 0.0510 & 26.3 \\
Foreign Born & 1.0223 & 0.2687 & \\
\hline
\end{tabular}

is greatest among the foreign born and least among the native born whites with native born black males falling in between.

Although these findings tend to support the contention that underenumeration is similarly biased, unfortunately they do not by themselves provide a direct estimate for the magnitude of the underenumeration to be expected in the nineteenth-century census materials. The following argument is presented to suggest that the extent of biased selection is sufficiently great to warrant an extensive exploration of the problem. It must be clearly understood, however, that the estimates presented in this discussion are merely benchmark figures derived from an indirect procedure.

In order to get a rough estimate of the magnitude of bias in the nineteenth-century census, we must utilize comparable estimates of underenumeration provided us by the systematic analysis of the modern census and attempt to adjust them according to what is known about the earlier censuses. It is now generally assumed that the 1950 U.S. census underenumerated whites by about $2.5 \%$ and nonwhites by about $12 \%$ to $13 \%$; or a relative underenumeration of nonwhites of about $10 \% .^{47} \mathrm{~A}$ 
comparison of the adjusted age ratios for white and black males computed for both periods of time suggest that this figure may be extrapolated backward to the nineteenth century as a plausible base estimate for the underenumeration for blacks relative to white natives. In the 1930-1950 U.S. censuses, the fluctuation in the adjusted age ratios for blacks was about three times that found for whites. ${ }^{48}$ This closely approximates the relative extent of variance calculated for the 1880-1900 U.S. censuses in Table 2 . These considerations support the tentative adoption of $10 \%$ as a reasonable national base estimate for the relative underenumeration of black natives to white natives in the late nineteenth-century census.

A similar line of argument leads to an estimate for the rate of underenumeration for foreign born males relative to native born males. Unfortunately, the critiques of mid-twentieth-century U.S. censuses do not estimate the extent of underreporting of foreign born in the modern period. As a result, a less directly comparable measure must be taken as the base figure. In this paper we apply the $10 \%$ rate which was found for the black population. However, this base must be adjusted in light of the calculations of internal error present in the earlier censuses. Table 2 indicates that, on the average, the fluctuation in the adjusted age ratios for foreign born males was more than two times as great as the fluctuation observed for blacks. Since the same deficiencies in census-taking give rise to both internal error and underenumeration, it seems reasonable to believe that the extent of relative underenumeration for the foreign born was about twice as great as that for the blacks. Perhaps, then, $20 \%$ can be used as a preliminary estimate for the net underenumeration of foreign born males relative to native white males.

\section{CONCLUSION}

The presence of underenumeration which is biased across important social groups poses a serious problem for analyzing census data. Studies of modern censuses and the internal inconsistencies found in the late nineteenth-century censuses 
suggest that relative bias is substantial. As a result, the differences in group characteristics cited in recent quantitative studies on such variables as mobility or persistence may merely be measuring the bias in the census and not real-world behavioral differences. For example, one might wish to compare the persistence rate of the native born and foreign born people in samples drawn from consecutive decennial U.S. censuses in the nineteenth century. Say that, in all three samples, more native born people were found ten years later in the next federal census than were foreign born people-arbitrarily, 20\% more native born for the 1830 sample, $10 \%$ more native born for the 1840 sample, and $10 \%$ more native born for the 1850 sample. However, two of these differences fall well within the general estimate of $20 \%$ for the extent of relative bias in the underenumeration of these two groups and the other one approximates the estimated figure. If the persistence rates are adjusted for the net underenumeration, then the differences tend to diminish. That is, it is possible to believe that the actual persistence rates were about the same-that some of the untraced foreign born in the samples were really living in the city ten years later, but the census did not record them. As a result, many of the important conclusions being drawn from the census regarding group differences in the degree to which the population turns over in a short period of time may be based solely on an artifact of the census data.

This line of reasoning with its tentative estimates, serves to illustrate the possible effects of biased census enumeration on the substantive findings of an important body of recent quantitative social history. The extent of underenumeration might have been sufficiently large to compromise the reliability of figures advanced in the literature for population turnover in nineteenth-century urban areas. Further, there appears to be some reason to believe that the differences in geographic mobility rates among economic classes as well as social groups were much less than has been suggested. It should be stressed, however, that this analysis does purport to refute the findings emerging from the mobility literature in particular. Rather, the 
intention has been to underscore the cautionary warnings regarding the census manuscript records which are always present in this literature. And, more importantly, we wish to identify census enumeration bias as a serious methodological problem with important substantive implications for current historical scholarship.

Although there are no easy solutions to the problem, one should not reject the manuscript census as a source of historical information. Other fields, particularly sociology and political science, have struggled with problems of biased sources with some limited success. ${ }^{49}$ Clearly, a concerted effort must be made by historians to analyze the manuscript census systematically in order to determine both the dimensions as well as degrees of bias due to underenumeration. Further, the areas in which biased enumeration is not a matter of immediate concern should be identified. We need to measure the limitations of our data with exactitude and more rigorously to control for their effects, or we will not be able to discern a fact of interest from the artifact of the data collection process.

\section{NOTES}

1. The advantages of using the manuscript census materials are reviewed in Stephan Thernstrom, "Reflections on the New Urban History," Daedalus, 100 (1971), 359-375.

2. Examples of this type of work are now legion. Some of the most recent contributions are: Richard J. Hopkins, "Occupational and Geographic Mobility in Atlanta, 1870-1890," Journal of Southern History, 34 (1968), 200-213: Stephan Thernstrom and Richard Sennett, eds., Nineteenth-Century Cities: Essays in the New Urban History (New Haven, 1969), particularly Parts I and II; Stephan Thernstrom and Peter R. Knights, "Men in Motion: Some Data and Speculations About Urban Population Mobility in Nineteenth Century America," Journal of Interdisciplinary History, 1 (1970), 7-35; Clyde Griffen, "Making it in America: Social Mobility in Mid-Nineteenth Century Poughkeepsie," New York History, 51 (1970), 479-499; Susan E. Bloomberg, Mary Frank Fox, Robert M. Warner, and Sam Bass Warner, Jr., "A Census Probe into Nineteenth Century Family History: Southern Michigan, 1850-1880," Journal of Social History, 5 (1971), 26-45; John Modell, "The Peopling of a Working Class Ward: Reading, Pennsylvania, 1850," Journal of Social History, 5 (1971), 71-95; Peter R. Knights, The Plain People of Boston, 1830-1860: A Study in City Growth (New York, 1971); Clyde Griffen, "Occupational Mobility in Nineteenth-Century America: Problems and Possibilities," Journal of Social History, 
5 (1972), 310-330; Elizabeth H. Pleck, "The Two-Parent Household: Black Family Structure in Late Nineteenth-Century Boston," Journal of Social History, 6, (1972), 3-31; David Gagan and Herbert Mays, "Historical Demography and Canadian Social History: Families and Land in Peel County, Ontario," Canadian Historical Review, 54 (1973), 27-47; Stephan Thernstrom, The Other Bostonians; Poverty and Progress in the American Metropolis, 1880-1970 (Cambridge, 1973).

3. W. E. Deming and F. F. Stephan, "On the Interpretation of Censuses as Samples," Journal of the American Statistical Association, 36 (1941), 45-49.

4. Edgar Z. Palmer, "The Correctness of the 1890 Census of Population for Nebraska Cities," Nebraska History, 82 (1951), 259-267; Sam B. Warner, Jr., Streetcar Suburbs: The Process of Growth in Boston, 1870-1900 (Cambridge, 1962), 171-178; T. H. Hollingsworth, Historical Demography (Ithaca, 1969), 107-108; Peter R. Knights, "A Method for Estimating Census Under-Enumeration," Historical Methods Newsletter, 3 (December, 1969), 5-8; Edward K. Muller, "Town Populations in the Early United States Censuses: An Aid to Research," Historical Methods Newsletter, 3 (March, 1970), 2-8; Margaret Walsh, "The Census as an Accurate Source of Information: The Value of Mid-Nineteenth Century Manufacturing Returns," Historical Methods Newsletter, 3 (September, 1970), 3-18; Thernstrom and Knights, "Men in Motion," 12-13; Robert G. Barrows, "The Manuscript Federal Census: Source for a "New' Local History," Indiana Magazine of History, 69 (1973), 189-190.

5. "Interview of the Select Committees of the Senate... and of the House of Representatives to make Provision for the Taking of the Tenth Census with Professor Francis A. Walker, Superintendent of the Census," Senate Miscellaneous Documents, Doc. No. 26, Vol. I, 45th Congress, 3rd Session, (December 17, 1878), p. 15.

6. Lemuel Shattuck, Report to the Committee at the City Council Appointed to obtain the Census of Boston for the Year 1845..., (Boston, 1846), 7-14; U.S. Census Office, Ninth Census, 1870, Vol. I (Washington, 1872), xix-xxxiv; U.S. Census Office, Compendium of the Tenth Census, 1880, Part I (Washington, 1883), xliii; "Letters Addressed to the Honorable John Davis, Concerning the Census of 1849 [sic] by Nahum Capen and Jesse Chickering," Senate Miscellaneous Documents, Document No. 64, Vol. I, 30th Congress, 2nd Session (March 3, 1849), 20-33; "Memorial of Mary F. Eastman, Henrietta L. T. Woolcott, and Others, Officers of the Association for the Advancement of Women, Praying that the Tenth Census May Contain a Just Enumeration of Women as Laborers and Producers," Senate Miscellaneous Documents, Doc. No. 84, Vol. II, 45th Congress, 2nd Session (June 15, 1878); The Federal Census: Critical Essays, Publications of the American Economic Association, New Series, No. 2, March 1899.

7. J.D.B. DeBow, A Statistical View of the United States..., (Washington, 1854), 192.

8. U.S. Census Office, Ninth Census, $1870, \mathrm{I}, \mathrm{xx}-\mathrm{xxi}$. The difference between the aggregate results of the two (separate) enumerations was about $2 \%$ in both cities. However, no test of case-by-case correspondence between the two enumeration lists was attempted.

9. Adna F. Weber, The Growth of Cities in the Nineteenth Century: A Study in Statistics (Ithaca, 1899, reprinted 1963), 26. Also see Henry Gannett, "The Alleged Census Frauds in the South," International Review, 10 (1881), 459-967.

10. Knights, "A Method for Estimating Census Under-Enumeration," 57. 
11. "Memorial of the American Statistical Association Pray ing for the Adoption of Measures for the Correction of Errors in the Returns of the Six th Census," Senate Documents, Doc. No. 5, Vol. I, 28th Congress, 2nd Session (December 10, 1844), p. 16.

12. Ibid., 17. This petition engendered considerable controversy. At issue was the whole question of the conditions under which blacks labored. Naturally, pro-slavery officials cited such statistics to show that blacks were "happier" under slavery than free. Dr. Edward Jarvis, the Massachusetts statistician and health reformer, initiated the at tack on the 1840 census in his "Insanity among the Coloured Population of the Free States," American Journal of the Medical Sciences (January, 1844), reprinted by T. K. and P. G. Collins (Philadelphia, 1844). Jarvis compared the census marshals' tally sheets with original manuscripts and in some cases found that officials in Washington had altered the figures. See Albert Deutsch, "The First U.S. Census of the Insane (1840) and its Use as Pro-Slavery Propaganda," Bulletin of the History of Medicine, 15 (1944), 469-482; see also Kelly Miller, "Enumeration Errors in the Negro Population," Scientific Monthly, 14 (1922), 168-177.

13. For a good introduction to the literature of modern census evaluation, see David M. Heer, ed., Social Statistics and the City; Report of a Conference Held in Washington, D.C., June 23, 1967 (Cambridge, 1968); and Carole W. Parsons, ed., America's Uncounted People (Washington, D.C., 1972). For a general bibliography see Slobodan S. Zarkovich, Quality of Statistical Data (Rome, 1966), 372-388.

14. For example, see U.S. Bureau of the Census, Infant Enumeration Study: 1950, Procedural Studies of the 1950 Census, No. 1 (1953); Eli S. Marks and Joseph Waksberg, "Evaluation of Coverage in the 1960 Census of Population through Case-by-Case Checking," Proceedings of the Social Statistics Section, American Statistical Association (1960), 62-70.

15. Ansley J. Coale, "The Population of the United States in 1950 Classified by Age, Sex, and Color-A Revision of Census Figures," Journal of the American Statistical Association, 50 (1955), 16-54; Donald J. Bogue, Bhasker D. Misra, and D. P. Danekar, "A New Estimate of the Negro Population and Negro Vital Rates in the United States, 1930-1960," Demography, 1 (1964), 339-358; Jacob S. Siegel and Melvin Zelnik, "An Evaluation of Coverage in the Census Population by Techniques of Demographic Analysis and by Composite Methods," Proceedings of the Social Statistics Section, American Statistical Association (1966), 71-85.

16. Ninth Census, 1870 , I, xxiii.

17. Ibid., xxi; Walker testimony (1878), 9-10. For general discussions of census-taking problems, see Carroll D. Wright, The History and Growth of the United States Census [17901890] Prepared for the Senate Committee on the Census (Washington, 1900); and Hyman Alterman, Counting People: The Census in History (New York, 1969).

18. Coale, "Population of the U.S. in 1950," 17.

19. R. J. Myers, "Errors and Bias in the Reporting of Ages in Census Data," Transactions of the Actuarial Society of America, 41 (1940), 395-415.

20. Coale, "Population of the U.S. in 1950," 23.

21. Available in Jacob S. Siegel, "Completeness of Coverage of the Nonwhite Population in the 1960 Census and Current Estimates and Some Implications," in Heer, ed., Social Statistics and the City, 13-54.

22. Peter R. Knights, "The Accuracy of Age Reporting in the Manuscript Federal Census of 1850 and 1860," Historical Methods Newsletter, 4 (1971), $79-83$. 
23. Ninth Census, 1870 , xxix.

24. Ibid.

25. For example, see U.S. Census Bureau, Special Reports of the Census Office, Twelfth Census: 1900, Supplemental Analysis, 139-143.

26. The primary method of evaluating underenumeration in the census employed by the study was a cross-checking procedure utilizing birth registration materials. The study assumes, therefore, a relatively complete listing of the infant population in the birth records. For an evaluation of this source, see C. Chandra Sekar and W. E. Deming, "On a Method of Estimating Birth and Death Rates and the Extent of Registration," Journal of the American Statistical Association, 44 (1949), 101-115; Sam Shapiro, "Estimating Birth Registration Completeness," Jcurnal of the American Statistical Association, 45 (1950), 261-264; and Sam Shapiro and Joseph Schachter, "Methodology and Summary Results of the 1950 Birth Registration Test in the United States," Estadistica, 10 (1952), 688-699.

Historians contemplating the use of noncensus materials to test the accuracy of the nineteenth-century census might well be interested in a portion of General Walker's congressional testimony cited above:

In 1870 the mortality returns made by the assistant marshals from a certain city were found to be inadequate. The city referred to contains more than a quarter of a million of inhabitants. It is one of the five or six largest cities in the United States. I sent my chief clerk thither to investiga te the facts and see if we could verify, and, if found defective, comple te, the returns from the city register. He found that the certificates of death upon which burial permits were issued were, so far as he could find out, in charge of a woman who appeared to perform menial service; the certificates were of ten made in pencil, not upon regular printed forms, but on scraps of paper of various shapes and sizes. My clerk reported that he did not believe that one-half of these certificates for the preceding year could be found: they had not been copied in to any register, they had not been filed in order or even numbered, but were thrown into a drawer where it was presumed they would remain, but where the manner in which they were kept gave no security that they were not raided upon for the purposes of lighting fires or wiping pens [Walker testimony $(1878), 13$.

27. Infant Enumeration: 1950, 1-2.

28. Ibid., Table 8, p. 47.

29. Leon Pritzker and N. D. Rothwell, "Procedural Dif ficulties in Taking Past Censuses in Predominantly Negro, Puerto Rican and Mexican Areas," in Heer, ed., Social Statistics and the City, 71-73.

30. Ibid., 6465 .

31. Ibid., 65; U.S. Bureau of the Census, U.S. Censuses of Population and Housing, 1960: Enumeration Time and Cost Study (Washington, 1963), Table 18, p. 33; "Ninth Census: Communications from Dr. Franklin B. Hough and Others, Relative to...," House Miscellaneous Documents, Doc. No. 33, Vol. 1, 41 st Congress, 1st Session (April 1, 1869), 22; and Walker testimony (December 17. 1878), 10.

32. Ninth Census, 1870, Vol. I, p. xx.

33. Infant Enumeration Study: 1950, Table 12, p. 57.

34. Bureau of the Census Technical Paper No. 9, 9. 
35. Ibid.; Pritzker and Rothwell, "Procedural Difficulties," 64-65.

36. "Communications from Dr. Franklin B. Hough ...," House Misc. Doc. (1869), 1, 21.

37. It is important to stress that merely because an individual is not found in the census manuscripts does not mean that he or she was absent from the home or has moved to another location. In fact, there is evidence that, at least for the mid-twentieth century, the very groups that are most underenumerated in the census also show lower, not higher, migration rates than the better-educated, white, middle-class community. See Athena Kottis, "Mobility and Human Capitol Theory: The Education, Age, Race and Income Characteristics of Migrants," Annals of Regional Science, 6 (1972), 41-60. One could hypothesize that, in addition to the demographic and economic factors we have outlined here, it is the daily not the annual movements of nonenumerated individuals which increased their chances of exclusion from the census manuscripts.

38. Ninth Census, 1870, Vol. I, xxii.

39. In order to best illustrate the methodological implications of bias in the census enumeration, we have chosen to focus our attention on the "persistence rate" measure commonly used in recent urban and social history studies. A general discussion of the statistical problems associated with nonsampling bias is beyond the scope of this essay. See Leslie Kish, Survey Sampling (New York, 1965), 509-571; R. Schlaifer, Introduction to Statistics for Business Decisions (New York, 1961), ch. 13; and Zarkovich, Quality of Statistical Data, 145-180.

Following Zarkovich (146-147), assume that a population has two strata, the first of which contains all those units which are included and complete in the survey and the second of which includes all the not-at-home, not-cooperative and not-found units. The size of the first group is $\mathrm{N}_{1}$ and the second $\mathrm{N}_{2}$ where

$$
\mathrm{N}_{1}+\mathrm{N}_{2}=\mathrm{N}
$$

Now set the "true value" of some particular characteristic $\bar{X}$ for a sample of N. We compute the arithmetic mean for the sample base solely on the collected portion of the population $\left(n_{1}\right)$ :

$$
\bar{x}=\frac{1}{n_{1}} \sum_{i}^{n_{1}} x_{i}
$$

with $E \bar{x}_{1}=\bar{X}_{1}$.

However, we desire to estimate:

$$
\bar{X}=\frac{1}{N}\left(N_{1} \bar{X}_{1}+N_{2} \bar{X}_{2}\right) .
$$

Therefore the expected bias is equal to: 


$$
\begin{aligned}
\overline{\mathrm{D}} & =\mathrm{Ex}_{1}-\overline{\mathrm{X}} \\
& =\overline{\mathrm{X}}_{1}-\overline{\mathrm{X}} \\
& =\frac{N_{2}}{\mathrm{~N}}\left(\overline{\mathrm{x}}_{1}-\overline{\mathrm{x}}_{2}\right) .
\end{aligned}
$$

Only when $\bar{x}_{1}=\bar{x}_{2}$ can we expect no bias to occur in our parameter estimates. As we have argued, in the "real world" this is unlikely to be the case.

40. Peter R. Knights, "Population Turnover, Persistence and Residential Mobility in Boston, 1830-1860," in Thernstrom and Sennett, eds., Nineteenth-Century Cities, 305-322.

41. Knights, Plain People of Boston, 55, 101, 105, 146.

42. U.S. Bureau of the Census, "The Post-Enumeration Survey: 1950," Bureau of the Census, Technical Paper No. 4, (Washington, 1960); and Pritzker and Rothwell, "Procedural Difficul ties."

43. Siegal and Zelnik, "Evaluation of Coverage in Census Population," 71-75.

44. Thernstrom and Knights, "Men in Motion," 7-35; Thernstrom, The Other Bostonians, 10-28, 279-288.

45. Coale, "Population of the U.S. in 1950," 24; and Kish, Survey Sampling, 529.

46. Coale, "Population of the U.S. in 1950," 20.

47. Ibid., 44; in addition to those sources cited above, see Daniel O. Price, "A Check on Underenumeration in the 1940 Census," American Sociological Review, 12 (1947), 44-49.

48. Coale, "Population of the U.S. in 1950," Figure 3, p. 22.

49. Kash, Survey Sampling, 509-571; Z. W. Birnbaum and M. G. Sirkin, "Bias Due to Non-Availability in Sampling Surveys," Journal of the American Statistical Association, 45 (1950), 98-111; Paul M. Siegel and Robert W. Hodge, "A Causal Approach to the Study of Measurement Error," in Hubert M. Blalock-and Ann B. Blalock, eds., Methodology in Social Research (New York, 1968), 28-59; H. M. Blalock, Caryll S. Wells, and Lesis F. Carter, "Statistical Estimation with Random Measurement Error," in E. F. Borgatta and G. W. Bohrnstadt, eds., Sociological Methodology: 1970 (San Francisco, 1970), 75-103. The only attempt by an historian to deal with these problems is Melvin A. Hammarberg, "Designing a Sample from Incomplete Historical Lists," American Quarterly, 23 (1971), 542-561. The Hammarberg method, however, assumes a relatively complete listing in the census. 